\title{
Stratification of Prognosis by Biological Features Following Neoadjuvant Chemotherapy in Luminal Breast Cancer
}

\author{
SHINYA YAMAMOTO ${ }^{1,2}$, TAKASHI CHISHIMA ${ }^{1}$, YUKAKO SHIBATA ${ }^{1}$, SHIORI INOUE $^{1}$, FUMI HARADA $^{1}$, \\ HIDEKI TAKEUCHI ${ }^{1}$, AKIMITSU YAMADA ${ }^{3}$, KAZUTAKA NARUI ${ }^{2}$ and ITARU ENDO ${ }^{3}$ \\ ${ }^{1}$ Department of Breast Surgery, Yokohama Rosai Hospital, Yokohama, Japan; \\ ${ }^{2}$ Department of Breast and Thyroid Surgery, Yokohama City University Medical Center, Yokohama, Japan; \\ ${ }^{3}$ Department of Gastroenterological Surgery, \\ Yokohama City University Graduate School of Medicine, Yokohama, Japan
}

\begin{abstract}
Background/Aim: There are few models predicting breast cancer prognosis among patients receiving neoadjuvant chemotherapy (NAC) for estrogen receptor (ER)-positivel human epidermal growth factor receptor 2 (HER2)-negative (luminal) breast cancer. We examined whether biological features (BFs) of residual tumors are prognostic factors following NAC. Patients and Methods: We enrolled patients with remnant tumors following NAC for luminal breast cancer and evaluated clinical stage, pathological stage, BFs prior to $N A C$, and BFs following NAC as prognostic factors. BFs were divided into high and low risk using the previously reported $Y R$-IHC4 model calculated according to ER, progesterone receptor $(P g R), H E R 2$, and the proliferation marker Ki-67. Results: A total of 57 patients were enrolled in the current study. We observed a statistically significant difference in relapse-free survival (RFS) between the BF risk categories via $Y R$-IHC4 predictions following NAC $(p=0.044)$. The 5-year $R F S$ rates of the BF low- and high-risk groups following NAC were $84.2 \%$ and $52.5 \%$, respectively. Conclusion: BFs of residual tumors following NAC may be important prognostic factors in luminal breast cancer.
\end{abstract}

Patients with breast cancer who achieve pathological complete response (pCR) following neoadjuvant chemotherapy (NAC) are reported to have improved event-free survival and overall survival (OS) (1). However, response-guided treatment

This article is freely accessible online.

Correspondence to: Takashi Chishima, Department of Breast Surgery, Yokohama Rosai Hospital, 3211 Kozukue-cho, Kohoku-ku, Yokohama City, Kanagawa 222-0036, Japan. Tel: +81 454748111, Fax: +81 454748323, e-mail: chishima-t@yokohamah.johas.go.jp

Key Words: Breast cancer, biological features, neoadjuvant chemotherapy, prognostic factors. following NAC has recently been administered to patients without pCR. For example, in patients with human epidermal growth factor receptor 2 (HER2)-positive breast cancer who present with residual invasive disease following NAC, prognoses were improved by changing the postoperative treatment to trastuzumab emtansine (from trastuzumab) (2).

Estrogen receptor (ER)-positive/HER2-negative (luminal) breast cancer, which accounts for $60-70 \%$ of all breast cancers $(3,4)$, has a low pCR rate (5) and lacks management evidence with respect to non-pCR cases. Thus, there is a need to identify non-pCR luminal breast cancer cases with high risk of recurrence.

Biological features $(\mathrm{BFs})$ and conventional anatomical factors are important prognostic factors (6). Oncotype DX recurrence scores (RS) are available as a means of expressing the BFs as predictive factors with respect to chemotherapy and overall prognostic factors (7). There are some reports that RS can be predicted using four immunostaining markers [ER, progesterone receptor $(\mathrm{PgR}), \mathrm{HER} 2$, and $\mathrm{Ki}-67]$ that are measured in daily clinical practice $(8,9)$. We also previously reported a model based on these four factors to predict RS $\geq 26$ (10). The cutoff value of 26 points is a guide in the TAILORx (11) and RxPONDER (12) trials.

Ueno et al. (13) reported that, in neoadjuvant endocrine therapy (NET), the combination of pre- and post-treatment RS provides pivotal information for predicting prognosis. However, to our knowledge, no study has examined the prediction of prognosis based only on the BFs of the residual tumors following NAC, in which physiology changes more dramatically than that following NET. In cases where NAC is performed, the BFs of remnant tumors following chemotherapy, compared to the initial BFs, may correlate with prognosis more strongly.

Herein, we examined whether the BFs of residual tumors following NAC could be a prognostic factor in luminal breast cancer. Our previously reported model was used to represent these BFs. 


\section{Patients and Methods}

Patients. Of 1,874 consecutively presenting patients who underwent surgery for primary breast cancer at Yokohama Rosai Hospital between June 2012 and August 2020, 63 had luminal breast cancer and underwent NAC. Six patients achieved pCR, and the remaining 57 patients had remnant tumors; these 57 patients were enrolled in this study. The study was approved by the Yokohama Rosai Hospital Ethics Committee (no. 2021-25) and was conducted in accordance with the principles of the Declaration of Helsinki and its later amendments. Consent was obtained using an opt-out system.

Immunohistochemical staining. Immunohistochemical (IHC) staining for ER, PgR, and Ki-67 was conducted using a Benchmark Ultra automated stainer and an Aperio ScanScope AT Turbo within the I-VIEW DAB Universal Kit (Roche Diagnostics KK, Tokyo, Japan). Quantitative scores, which were expressed as the proportion of positively stained cells for each marker, were calculated. Five areas were randomly selected, and approximately 1,000 cells were counted in each area to obtain the average scores for each marker. According to previous research, ER positivity is defined as an ERpositive cell rate of $>10 \%$ (14). IHC staining for HER2 was performed using a DAKO Autostainer Link 48 (Agilent Technologies, Ltd., Tokyo, Japan) and the DAKO HercepTest II Kit (DAKO, Glostrup, Denmark). IHC staining for HER2 was evaluated based on the following scoring system: $0+, 1+, 2+$, and $3+$. The criterion for HER 2 negativity was a score of $0+, 1+$, or $2+$, with a fluorescence in situ hybridization score of <2.0 (15).

Risk categories of BFs via the discriminant function. We previously demonstrated that a model based on four markers (ER, PgR, HER2, $\mathrm{Ki}-67$ ) could predict $\mathrm{RS} \geq 26$ (10). The discriminant function was as

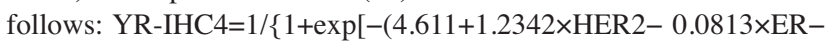
$0.0489 \times \mathrm{PgR}+0.0857 \times \mathrm{Ki}-67)]\}$. Quantitative values (i.e., the proportion of positively stained cells for each marker) were used for the above modes for ER, PgR, and Ki-67, whereas scores of 0 , 1, and 2 were used for HER2. The cut-off point for YR-IHC4 was 0.5. If YR-IHC4 was $\geq 0.5$, the case was defined as high risk; and if YRIHC4 was $<0.5$, the case was defined as low risk.

TNM classification. Anatomical staging was assessed using the Union for International Cancer Control (UICC) tumor node metastasis (TNM) classification, 8th edition (16).

Neoadjuvant chemotherapy indication and regimens. NAC was performed according to BFs and anatomical staging, based on the physician's discretion. NAC includes both anthracycline-based and taxane-based regimens. Dose modification was performed because of adverse events according to patient or physician request.

One of the following regimens was implemented as an anthracyclinebased regimen: four cycles of FEC (cyclophosphamide $500 \mathrm{mg} / \mathrm{m}^{2}$, epirubicin $100 \mathrm{mg} / \mathrm{m}^{2}$, fluorouracil $500 \mathrm{mg} / \mathrm{m}^{2}$ ) every 3 weeks, four cycles of EC (cyclophosphamide $600 \mathrm{mg} / \mathrm{m}^{2}$, epirubicin $90 \mathrm{mg} / \mathrm{m}^{2}$ ) every 3 weeks, or four cycles of dose-dense EC (cyclophosphamide $600 \mathrm{mg} / \mathrm{m}^{2}$, epirubicin $90 \mathrm{mg} / \mathrm{m}^{2}$ ) every 2 weeks.

One of the following regimens was used as a taxane-based regimen: four cycles of docetaxel $\left(75 \mathrm{mg} / \mathrm{m}^{2}\right)$ every 3 weeks, 12 cycles of paclitaxel $\left(80 \mathrm{mg} / \mathrm{m}^{2}\right)$ on a weekly basis, or 4 cycles of dose-dense paclitaxel $\left(175 \mathrm{mg} / \mathrm{m}^{2}\right)$ every 2 weeks.

Adjuvant therapy following surgery. Endocrine therapy was performed postoperatively. Tamoxifen was used for premenopausal patients, and aromatase inhibitors were used for postmenopausal patients. However, this regimen was changed as appropriate based on occurrence of adverse events. Irradiation was performed for cases requiring breast-conserving surgery and in those with axillary lymph node metastasis prior to NAC. In cases that had undergone total mastectomy with three or fewer lymph node metastases following NAC, radiation therapy was not administered following a discussion between the patient and the physician. Capecitabine was likewise administered following discussions between the physician and the patient.

Prognostic factors. We evaluated the following prognostic factors in the present study: clinical stage prior to NAC, pathological stage following NAC, risk category of BF via YR-IHC4 predictions prior to $\mathrm{NAC}$, and risk category of $\mathrm{BF}$ via $\mathrm{YR}-\mathrm{IHC} 4$ predictions following NAC.

Statistical analysis. Cox proportional hazard models were used to examine prognostic factors with respect to relapse-free survival (RFS) and OS via hazard ratios (HR) and 95\% confidence intervals (CIs). RFS and OS were estimated using the Kaplan-Meier method. Statistical significance was defined based on a two-sided $p$-value $<0.05$. All statistical analyses were performed using Bell Curve software (version 3.20) for Excel (Social Survey Research Information, Tokyo, Japan).

\section{Results}

Patient characteristics. The medical and demographic characteristics of the patients included in the present study are shown in Table I. We enrolled 24 (42.1\%) and 33 (57.9\%) patients with cStage II and cStage III, respectively, as well as $16(28.1 \%), 25(43.8 \%)$, and $16(28.1 \%)$ patients with pStage I, pStage II, and pStage III, respectively. Prior to NAC, there were $34(59.6 \%)$ and $22(38.5 \%)$ patients at low risk and high risk, respectively, according to the YR-IHC4 model. There was insufficient data to calculate YR-IHC4 predictions for one case. Following NAC, there were $43(75.4 \%)$ and 14 $(24.5 \%)$ patients at low risk and high risk, respectively.

Information regarding therapy after surgery is shown in Table II. Endocrine therapy after surgery was performed in 56 patients $(98.3 \%)$. Radiation therapy was administered to 50 patients $(87.7 \%)$. Capecitabine was administered to 23 patients $(40.3 \%)$.

Relapse-free and overall survival. The median follow-up time in the current study was 46 months (range $=8-110$ months). The results of Cox proportional hazard analysis are shown in Table III. We observed a statistically significant difference in RFS between risk categories of BF via YR- 
Table I. Patient medical and demographic characteristics.

\begin{tabular}{lc}
\hline Variable & Number of patients $(\%)$ \\
\hline Age (year; median) & $51(29-71)$ \\
Menopausal status & \\
Premenopausal & $31(54.4)$ \\
Postmenopausal & $26(45.6)$ \\
Histological type & \\
Invasive ductal carcinoma & $51(89.4)$ \\
Other & $3(5.3)$ \\
Unknown & $3(5.3)$ \\
Nuclear grade before NAC & \\
1 & $7(12.3)$ \\
2 & $26(45.6)$ \\
3 & $23(40.3)$ \\
Unknown & $1(1.7)$ \\
LVI before NAC & \\
Present & $23(40.3)$ \\
Absent & $29(50.9)$ \\
Unknown & $5(8.8)$ \\
cStage before NAC & \\
II & $24(42.1)$ \\
III & $33(57.9)$ \\
pStage after NAC & \\
I & $16(28.1)$ \\
II & $25(43.8)$ \\
III & $16(28.1)$ \\
BF prior to NAC & $34(59.6)$ \\
Low-risk & $22(38.5)$ \\
High-risk & $1(1.7)$ \\
Unknown & \\
BF following NAC & $43(75.4)$ \\
Low risk & $14(24.5)$ \\
High risk & \\
\hline & \\
\hline &
\end{tabular}

NAC: Neoadjuvant chemotherapy; LVI: lymphovascular invasion; BF: biological feature.

IHC4 predictions following NAC, with an HR of 3.578 $(1.033-12.388 ; \quad p=0.044)$. No statistically significant differences in OS were observed for any of the prognostic factors. Kaplan-Meier curves for RFS are shown in Figure 1. The 5-year RFS rates were $84.2 \%$ and $52.5 \%$ in the lowrisk and high-risk groups of BFs via YR-IHC4 predictions following NAC, respectively.

\section{Discussion}

To the best of our knowledge, this is the first report to show that prognosis is stratified only by BFs of residual tumors following NAC.

Several previous studies have examined prognosis prediction following NAC. Colleoni et al. (17) reported a nomogram predicting disease-free survival (DFS) in patients without $\mathrm{pCR}$ following NAC. In their study, five-year DFS was predicted based on factors including pathological tumor size, the number of positive lymph nodes, ER expression, HER2 status, Ki-67,
Table II. Descriptive statistics for adjuvant therapy performed following surgery.

\begin{tabular}{lc}
\hline Therapy & Number of patients (\%) \\
\hline Endocrine therapy & \\
Performed & $56(98.3)$ \\
Not performed & $1(1.7)$ \\
Radiation therapy & \\
$\quad$ Performed & $50(87.7)$ \\
$\quad$ Not performed & $7(12.3)$ \\
Chemotherapy (Capecitabine) & \\
Performed & $23(40.3)$ \\
Not performed & $34(59.6)$ \\
\hline
\end{tabular}

Table III. Associations observed within Cox proportional hazard models.

\begin{tabular}{|c|c|c|c|c|}
\hline \multirow[b]{2}{*}{ Variable } & \multicolumn{2}{|l|}{ RFS } & \multicolumn{2}{|l|}{ OS } \\
\hline & HR $(95 \% \mathrm{CI})$ & $p$-Value & $\mathrm{HR}(95 \% \mathrm{CI})$ & $p$-Value \\
\hline cStage & & 0.240 & & 0.613 \\
\hline Stage II & Referent & & Referent & \\
\hline Stage III & $\begin{array}{c}2.259 \\
(0.579-8.819)\end{array}$ & & $\begin{array}{c}2.048 \\
(0.126-33.075)\end{array}$ & \\
\hline pStage & & 0.068 & & 0.255 \\
\hline Stage I/II & Referent & & Referent & \\
\hline Stage III & $\begin{array}{c}3.189 \\
(0.916-11.096)\end{array}$ & & $\begin{array}{c}5.000 \\
(0.312-79.937)\end{array}$ & \\
\hline $\begin{array}{l}\text { BF prior to } \\
\text { NAC }\end{array}$ & & 0.898 & & - \\
\hline Low-risk & Referent & & - & \\
\hline High-risk & $\begin{array}{c}0.920 \\
(0.259-3.265)\end{array}$ & & - & \\
\hline $\begin{array}{l}\text { BF following } \\
\text { NAC }\end{array}$ & & 0.044 & & 0.325 \\
\hline Low-risk & Referent & & Referent & \\
\hline High-risk & $\begin{array}{c}3.578 \\
(1.033-12.388)\end{array}$ & & $\begin{array}{c}4.053 \\
(0.249-65.798)\end{array}$ & \\
\hline
\end{tabular}

HR: Hazard ratio; NAC: neoadjuvant chemotherapy; OS: overall survival; RFS: relapse-free survival; BF: biological feature.

and vascular invasion. Another evaluation method, the CPS+EG staging system incorporating ER status, tumor grade with pretreatment clinical stage (CS), and post-treatment pathologic stage (PS), has likewise been reported and is well discussed (18-21). These studies differ from the present study in that they addressed anatomical factors and included HER2positive cases and did not evaluate $\mathrm{PgR}$, which is a strong prognostic factor for luminal breast cancer (22). In addition, ER status prior to NAC was evaluated using the CPS+EG Staging System. In contrast, our research focuses on luminal breast cancer and only on the BFs of residual tumors.

We observed that clinical stage and BFs prior to NAC did not stratify prognoses. There may be bias underlying these 


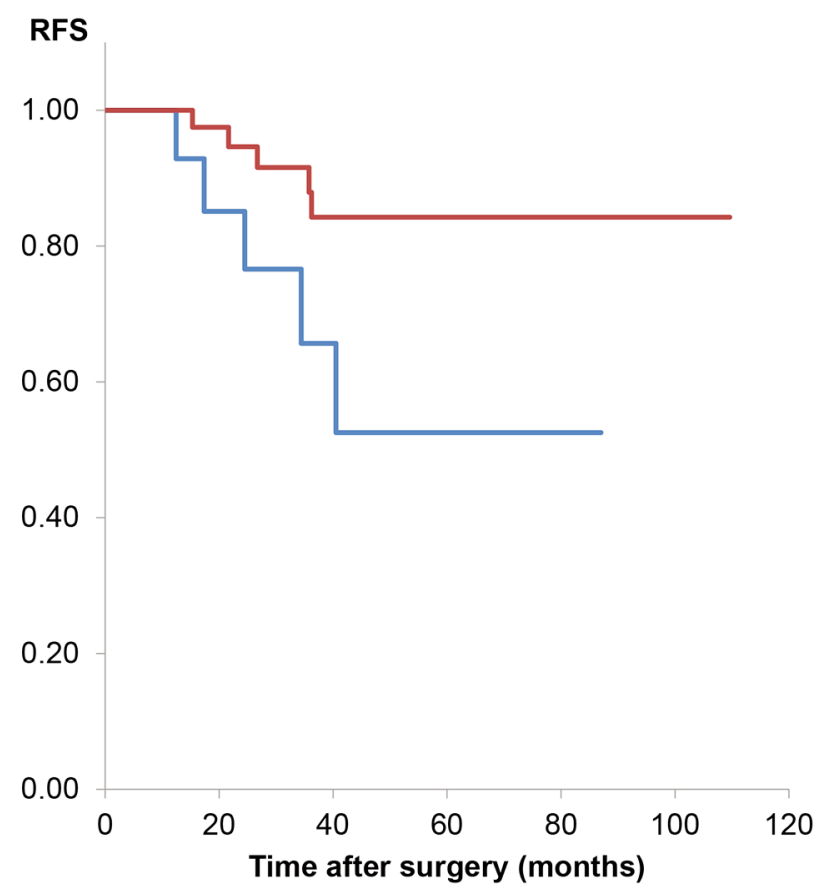

-High risk

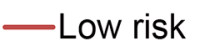

Figure 1. Kaplan-Meier curves for relapse-free survival (RFS). The 5year RFS rates were $84.2 \%$ and $52.5 \%$ in the low-risk and high-risk groups of biological features via YR-IHC4 predictions following neoadjuvant chemotherapy, respectively.

findings in that patients with a good prognosis who do not require chemotherapy or $\mathrm{pCR}$ following NAC were not enrolled in the current investigation. On the contrary, although a statistically significant difference was not observed, we found that RFS was stratified based on pathological stage. Thus, if the number of cases is large, pathological stage may also be an important factor. With respect to OS, no statistically significant differences were observed for any of the prognostic factors in the current investigation. This could be because the sample size was small, and the prognosis for luminal breast cancer is relatively long, therefore, it is hardto make a significant difference.

Recently, response-guided treatment following NAC has been performed for non-pCR cases as an escalation therapy. Masuda et al. (23) reported that the addition of capecitabine, an oral fluoropyrimidine, prolongs DFS and OS among patients with HER2-negative breast cancer who present with residual tumors following NAC. In our study, capecitabine was administered to 23 of the 57 enrolled patients (40.3\%). We note that the present study includes cases enrolled prior to the initiation of the above trial. Rather than administering capecitabine to all non-pCR cases, the strategy of administering capecitabine only to high-risk cases among non-pCR cases may be beneficial to patients as well as in consideration of medical costs. In the present study, as the number of enrolled cases was small, it was not possible to examine the additional benefit of capecitabine. The results of the Monarch E trial were announced in 2020 (24); the results demonstrated that in patients with luminal high-risk breast cancer, the CDK4/6 inhibitor abemaciclib in addition to endocrine therapy demonstrated superior DFS compared to endocrine therapy alone. For high-risk cases following NAC, CDK4/6 inhibitors have shown promise. Conversely, low-risk cases may not require escalation therapy even in non-pCR cases. The present study results provide important insights for identifying cases requiring additional treatment among non-pCR cases following NAC for luminal breast cancer. This is important as a de-escalation within escalation therapy. Evaluating the kind of additional treatment that should be administered to various non-pCR cases is an urgent issue that should be addressed comprehensively in future investigations.

The present study has several limitations. First, the YRIHC4 model used in the present study has not been proven or validated in a large-scale clinical trial. Originally, RS have been shown to predict prognosis based on specimens obtained prior to chemotherapy; therefore, it is unclear whether these predictions are applicable to specimens obtained following NAC. In addition, the current study was conducted at a single institution with a small patient population; furthermore, the study design was retrospective. Future prospective multi-center studies with larger cohorts are necessary in order to validate our findings.

\section{Conclusion}

In the current study, we demonstrated that the biological features of residual tumors evaluated following NAC may be important prognostic factors in luminal breast cancer. In the future, we aim to create a model identifying vulnerable subpopulations with poor prognoses following NAC for luminal breast cancer in a high-powered multi-center investigation with a larger number of enrolled patients and to conduct prospective randomized trials regarding additional treatment modalities for this population with a poor prognosis.

\section{Conflicts of Interest}

The Authors have no conflicts of interest to disclose in relation to this study.

\section{Authors' Contributions}

SY designed the study, collected the samples and clinical data, performed statistical analyses, and wrote the article. TC collected the samples and clinical data, designed the study, and revised the 
article. YS, SI, FH, and HT collected samples and clinical data. AY, $\mathrm{KN}$, and IE have revised the manuscript. All Authors have read and approved the final version of the manuscript.

\section{References}

1 Cortazar P, Zhang L, Untch M, Mehta K, Costantino JP, Wolmark N, Bonnefoi H, Cameron D, Gianni L, Valagussa P, Swain SM, Prowell T, Loibl S, Wickerham DL, Bogaerts J, Baselga J, Perou C, Blumenthal G, Blohmer J, Mamounas EP, Bergh J, Semiglazov V, Justice R, Eidtmann H, Paik S, Piccart M, Sridhara R, Fasching PA, Slaets L, Tang S, Gerber B, Geyer CE Jr, Pazdur R, Ditsch N, Rastogi P, Eiermann W and von Minckwitz G: Pathological complete response and long-term clinical benefit in breast cancer: the CTNeoBC pooled analysis. Lancet 384(9938): 164-172, 2014. PMID: 24529560. DOI: 10.1016/S0140-6736(13)62422-8

2 von Minckwitz G, Huang CS, Mano MS, Loibl S, Mamounas EP, Untch M, Wolmark N, Rastogi P, Schneeweiss A, Redondo A, Fischer HH, Jacot W, Conlin AK, Arce-Salinas C, Wapnir IL, Jackisch C, DiGiovanna MP, Fasching PA, Crown JP, Wülfing P, Shao Z, Rota Caremoli E, Wu H, Lam LH, Tesarowski D, Smitt M, Douthwaite H, Singel SM, Geyer CE Jr and KATHERINE Investigators: Trastuzumab emtansine for residual invasive HER2-positive breast cancer. N Engl J Med 380(7): 617-628, 2019. PMID: 30516102. DOI: 10.1056/ NEJMoa 1814017

3 O'Brien KM, Cole SR, Tse CK, Perou CM, Carey LA, Foulkes WD, Dressler LG, Geradts J and Millikan RC: Intrinsic breast tumor subtypes, race, and long-term survival in the Carolina Breast Cancer Study. Clin Cancer Res 16(24): 6100-6110, 2010. PMID: 21169259. DOI: 10.1158/1078-0432.CCR-10-1533

4 Troester MA, Sun X, Allott EH, Geradts J, Cohen SM, Tse CK, Kirk EL, Thorne LB, Mathews M, Li Y, Hu Z, Robinson WR, Hoadley KA, Olopade OI, Reeder-Hayes KE, Earp HS, Olshan AF, Carey LA and Perou CM: Racial differences in PAM50 subtypes in the Carolina Breast Cancer Study. J Natl Cancer Inst 110(2): 176-182, 2018. PMID: 28859290. DOI: 10.1093/ jnci/djx 135

5 Haque W, Verma V, Hatch S, Suzanne Klimberg V, Brian Butler $\mathrm{E}$ and Teh BS: Response rates and pathologic complete response by breast cancer molecular subtype following neoadjuvant chemotherapy. Breast Cancer Res Treat 170(3): 559-567, 2018. PMID: 29693228. DOI: 10.1007/s10549-018-4801-3

6 McVeigh TP and Kerin MJ: Clinical use of the Oncotype DX genomic test to guide treatment decisions for patients with invasive breast cancer. Breast Cancer (Dove Med Press) 9: 393 400, 2017. PMID: 28615971. DOI: 10.2147/BCTT.S109847

7 Paik S, Tang G, Shak S, Kim C, Baker J, Kim W, Cronin M, Baehner FL, Watson D, Bryant J, Costantino JP, Geyer CE Jr, Wickerham DL and Wolmark N: Gene expression and benefit of chemotherapy in women with node-negative, estrogen receptorpositive breast cancer. J Clin Oncol 24(23): 3726-3734, 2006. PMID: 16720680. DOI: 10.1200/JCO.2005.04.7985

8 Cuzick J, Dowsett M, Pineda S, Wale C, Salter J, Quinn E, Zabaglo L, Mallon E, Green AR, Ellis IO, Howell A, Buzdar AU and Forbes JF: Prognostic value of a combined estrogen receptor, progesterone receptor, $\mathrm{Ki}-67$, and human epidermal growth factor receptor 2 immunohistochemical score and comparison with the Genomic Health recurrence score in early breast cancer. J Clin Oncol 29(32): 4273-4278, 2011. PMID: 21990413. DOI: 10.1200/JCO.2010.31.2835

9 Klein ME, Dabbs DJ, Shuai Y, Brufsky AM, Jankowitz R, Puhalla SL and Bhargava R: Prediction of the Oncotype DX recurrence score: use of pathology-generated equations derived by linear regression analysis. Mod Pathol 26(5): 658-664, 2013. PMID: 23503643. DOI: 10.1038/modpathol.2013.36

10 Yamamoto S, Chishima T, Shibata Y, Harada F, Takeuchi H, Yamada A, Narui K, Misumi T, Ishikawa T and Endo I: Clinical impact of a novel model predictive of oncotype DX recurrence score in breast cancer. In Vivo 35(4): 2439-2444, 2021. PMID: 34182528. DOI: 10.21873 /invivo. 12522

11 Sparano JA, Gray RJ, Makower DF, Pritchard KI, Albain KS, Hayes DF, Geyer CE Jr, Dees EC, Goetz MP, Olson JA Jr, Lively T, Badve SS, Saphner TJ, Wagner LI, Whelan TJ, Ellis MJ, Paik S, Wood WC, Ravdin PM, Keane MM, Gomez Moreno HL, Reddy PS, Goggins TF, Mayer IA, Brufsky AM, Toppmeyer DL, Kaklamani VG, Berenberg JL, Abrams J and Sledge GW Jr: Adjuvant chemotherapy guided by a 21-gene expression assay in breast cancer. N Engl J Med 379(2): 111-121, 2018. PMID: 29860917. DOI: 10.1056/NEJMoa1804710

12 Ramsey SD, Barlow WE, Gonzalez-Angulo AM, Tunis S, Baker L, Crowley J, Deverka P, Veenstra D and Hortobagyi GN: Integrating comparative effectiveness design elements and endpoints into a phase III, randomized clinical trial (SWOG S1007) evaluating oncotypeDX-guided management for women with breast cancer involving lymph nodes. Contemp Clin Trials 34(1): 1-9, 2013. PMID: 23000081. DOI: 10.1016/j.cct.2012.09.003

13 Ueno T, Saji S, Masuda N, Iwata H, Kuroi K, Sato N, Takei H, Yamamoto Y, Ohno S, Yamashita H, Hisamatsu K, Aogi K, Sasano $\mathrm{H}$ and Toi M: Changes in Recurrence Score by neoadjuvant endocrine therapy of breast cancer and their prognostic implication. ESMO Open 4(1): e000476, 2019. PMID: 30962956. DOI: 10.1136/esmoopen-2018-000476

14 Fujii T, Kogawa T, Dong W, Sahin AA, Moulder S, Litton JK, Tripathy D, Iwamoto T, Hunt KK, Pusztai L, Lim B, Shen Y and Ueno NT: Revisiting the definition of estrogen receptor positivity in HER2-negative primary breast cancer. Ann Oncol 28(10): 2420-2428, 2017. PMID: 28961844. DOI: 10.1093/ annonc/mdx397

15 Wolff AC, Hammond MEH, Allison KH, Harvey BE, Mangu PB, Bartlett JMS, Bilous M, Ellis IO, Fitzgibbons P, Hanna W, Jenkins RB, Press MF, Spears PA, Vance GH, Viale G, McShane LM and Dowsett M: Human epidermal growth factor receptor 2 testing in breast cancer: American Society of Clinical Oncology/College of American Pathologists clinical practice guideline focused update. J Clin Oncol 36(20): 2105-2122, 2018. PMID: 29846122. DOI: 10.1200/JCO.2018.77.8738

16 Brierley JD, Gospodarowicz MK and Wittekind C: TNM Classification of Malignant Tumours. Hoboken, NJ, John Wiley \& Sons, 2017.

17 Colleoni M, Bagnardi V, Rotmensz N, Dellapasqua S, Viale G, Pruneri G, Veronesi P, Torrisi R, Luini A, Intra M, Galimberti V, Montagna E and Goldhirsch A: A risk score to predict diseasefree survival in patients not achieving a pathological complete remission after preoperative chemotherapy for breast cancer. Ann Oncol 20(7): 1178-1184, 2009. PMID: 19218304. DOI: 10.1093/annonc/mdn747

18 Abdelsattar JM, Al-Hilli Z, Hoskin TL, Heins CN and Boughey JC: Validation of the CPS+EG staging system for disease- 
specific survival in breast cancer patients treated with neoadjuvant chemotherapy. Ann Surg Oncol 23(10): 3206-3211, 2016. PMID: 27328945. DOI: 10.1245/s10434-016-5324-y

19 Xu L, Liu Y, Fan Z, Jiang Z, Liu Y, Ling R, Zhang J, Yu Z, Jin F, Wang C, Cui S, Wang S, Mao D, Han B, Wang T, Zhang G, Wang T, Guo B, Yu L, Xu Y, Fu F, Liu Z, Wang S, Luo K, Xiang Q, Zhang Z, Liu Q, Zhou B, Liu Z, Ma C, Tong W, Mao J, Duan $\mathrm{X}$ and Cui Y: Assessment of CPS+EG, neo-bioscore and modified neo-bioscore in breast cancer patients treated with preoperative systemic therapy: a multicenter cohort study. Front Oncol 11: 606477, 2021. PMID: 33796452. DOI: 10.3389/ fonc.2021.606477

20 Mittendorf EA, Jeruss JS, Tucker SL, Kolli A, Newman LA, Gonzalez-Angulo AM, Buchholz TA, Sahin AA, Cormier JN, Buzdar AU, Hortobagyi GN and Hunt KK: Validation of a novel staging system for disease-specific survival in patients with breast cancer treated with neoadjuvant chemotherapy. J Clin Oncol 29(15): 1956-1962, 2011. PMID: 21482989. DOI: 10.1200/JCO.2010.31.8469

21 Hasegawa Y, Matsubara N, Kogawa T, Naito Y, Harano K, Hosono A, Onishi T, Hojo T, Shimokawa M and Mukohara T: Neo-bioscore in guiding post-surgical therapy in patients with triple-negative breast cancer who received neoadjuvant chemotherapy. In Vivo 35(2): 1041-1049, 2021. PMID: 33622900. DOI: 10.21873/invivo.12348

22 Kurozumi S, Matsumoto H, Hayashi Y, Tozuka K, Inoue K, Horiguchi J, Takeyoshi I, Oyama T and Kurosumi M: Power of PgR expression as a prognostic factor for ER-positive/HER2negative breast cancer patients at intermediate risk classified by the Ki67 labeling index. BMC Cancer 17(1): 354, 2017. PMID: 28532429. DOI: $10.1186 / \mathrm{s} 12885-017-3331-4$
23 Masuda N, Lee SJ, Ohtani S, Im YH, Lee ES, Yokota I, Kuroi K, Im SA, Park BW, Kim SB, Yanagita Y, Ohno S, Takao S, Aogi K, Iwata H, Jeong J, Kim A, Park KH, Sasano H, Ohashi $\mathrm{Y}$ and Toi M: Adjuvant capecitabine for breast cancer after preoperative chemotherapy. N Engl J Med 376(22): 2147-2159, 2017. PMID: 28564564. DOI: 10.1056/NEJMoa1612645

24 Johnston SRD, Harbeck N, Hegg R, Toi M, Martin M, Shao ZM, Zhang QY, Martinez Rodriguez JL, Campone M, Hamilton E, Sohn J, Guarneri V, Okada M, Boyle F, Neven P, Cortés J, Huober J, Wardley A, Tolaney SM, Cicin I, Smith IC, Frenzel M, Headley D, Wei R, San Antonio B, Hulstijn M, Cox J, O'Shaughnessy J, Rastogi P and monarchE Committee Members and Investigators: Abemaciclib combined with endocrine therapy for the adjuvant treatment of HR+, HER2-, node-positive, highrisk, early breast cancer (monarchE). J Clin Oncol 38(34): 3987 3998, 2020. PMID: 32954927. DOI: 10.1200/JCO.20.02514
Received December 2, 2021

Revised December 20, 2021 Accepted December 21, 2021 